\title{
@s outr@s cariocas: homoerotismo, hegemonia e história*
}

\section{Osmundo Pinho**}

Aceitar que as formas de opressão sexual, ou melhor, que os modos históricos de construção de sujeitos sexualizados, são modos concretos de exercício de poder e de construção de hegemonia, seria condição preliminar para compreender como o sexo e o desejo têm sido socialmente significados. As desigualdades de gênero, classe e raça, assim, eroticamente conectadas, ganham uma outra face, eventualmente negligenciada, que as faz adquirir densidade corporal $e$ materialidade histórica. A injustiça erótica e a injustiça social partilham, nesse caso, o mesmo leito. E aqueles sujeitos "abjetos", codificados e circunscritos, estiveram, e ainda estão, sujeitos à violência, à exploração (inclusive sexual) e ao apagamento.

Ao realizar uma "genealogia crítica do homoerotismo" no Rio de Janeiro, Carlos Figari, nos convida a aprofundar essa compreensão, de como o desejo se conecta à ideologia e esta se consolida como formação hegemônica. Não que ele pressuponha um sujeito homossexual a-histórico e prévio à sua elaboração/ sujeição pelo discurso médico e pelas forças patriarcais do estado moderno, mas, de modo inverso, justamente nos revela os campos de força discursivos e históricos, que circunscrevem, como "bordas", as possibilidades de significação para a prática homossexual. Aquilo que está indicado neste livro como um

\footnotetext{
"Resenha de FIGARI, Carlos. @s Outr@s Cariocas. Interpelações, Experiências e Identidades Homoeróticas no Rio de Janeiro. Século XVII ao XX. Belo Horizonte/Rio de Janeiro, Editora da UFMG/IUERJ, 2007. Recebida para publicação em agosto de 2008, aceita em setembro de 2008.

** Professor Adjunto do Centro de Artes, Humanidades e Letras Universidade Federal do Recôncavo da Bahia, Campus de Cachoeira. osmundop@ig.com.br
} 
Homoerotismo, hegemonia e história

campo de "conformação" para a experiência vivida homossexual. Tal campo foi instituído, no Rio de Janeiro, assim como na América Latina, sob a forma de uma hegemonia colonial, caracterizada por estruturas sociais altamente hierarquizadas $e$ violentas e, em termos discursivos, tenderia para a constituição de unidade ou fechamento, contra a existência hiper-proliferante das diversas e prometéicas formas do desejo.

A intenção manifesta da pesquisa ${ }^{1}$ foi produzir uma "fenomenologia" dos comportamentos homoeróticos no Rio de Janeiro no curso de quatro séculos. É bem evidente, então, que o problema histórico do anacronismo deveria ser criticamente considerado. E assim o foi, com originalidade e rigor pelo autor. Na medida em que é através da reconstrução discursiva de vozes apagadas, definidas como Outras por outros, que Figari pode desenhar sua cartografia histórico-fenomenológica. Ora, justamente porque esses sujeitos e suas práticas aparecem inscritos pela voz ideológica hegemônica, que os re-interpreta $e$, na verdade, os produz discursivamente, é que é possível interpelá-los ${ }^{2}$ em seu caráter de contra-ideológico.

A ideologia, que fixa o significante sobre o sexo como uma imposição discursiva, é instrumento e meio de uma hegemonia, que manifesta seu poder não exatamente sobre os corpos, mas propriamente os constituindo discursivamente. Ao garantir que o Outro da representação não seja capaz, não encontre meio, espaço ou linguagem para representar a si mesmo, essa mesma representação constitui uma impossibilidade lógica, histórica e política a um só tempo. Porque, diríamos, como, sob o peso do silenciamento e da irredutibilidade, as "vozes nativas" dos

1 Que deu origem a tese de doutorado defendida no IUPERJ em 2003, e que é a forma original deste livro.

2 A idéia de interpelação advém, obviamente, de Althusser, para quem ideologias só existem através de práticas, envolvidas na dinâmica concreta de relações sociais, só existindo e "funcionando" através dos sujeitos, constituindoos e interpelando-os individualmente, ou melhor, construindo-os através dessa interpelação (Althusser, 1992). 
"tiviras", "cudinas", "quimbandas" e "jimbandas", sujeitos de uma sexualidade dissidente, poderiam ser ouvidas? Ainda assim, e com grande mérito, Carlos pode desencavar fissuras, "nodos de não-sutura", que permitem flagrar a existência contra-hegemônica e problemática desses corpos e desejos.

Remetendo-se aos primórdios da colonização, ele define, em primeiro lugar, o que chama de texto "nativo-brasileiro" $e$ "nativo-africano", desentranhados dos registros históricos da alteridade, realizados pelos cronistas-escribas da época. De tal forma, somos surpreendidos pela aparição dessas figuras sedutoras e obscuras dos sodomitas "nativos", selvagens infensos a partição ocidental entre corpo e alma (Focault, 2004). Do interior das vozes autorizadas pela História, Carlos faz emergir, assim, o texto "colonial subalterno", como palimpsesto dessas vozes parcialmente assujeitadas. O fundamental parece ser, nesse caso, a visualização da economia política colonial, baseada no trabalho escravo e na sujeição dos corpos Outros, no ambiente da plantation e dos mercados transatlânticos. Ora, como coloca Young (2002), o comércio dos corpos (pré)racializados, e o comércio sexual entre os corpos, no ambiente da desigualdade radical, é o núcleo duro dessa economia política, que aparece sob a forma ideológica da miscigenação colonial:

É claro que as formas de troca sexual desenvolvidas pelo colonialismo eram elas próprias, tanto reflexo como conseqüências, dos modos econômicos de troca, constitutivos da base das relações coloniais. ${ }^{3}$

A alteridade radical entre, inicialmente, cristãos (europeus) e gentios (nativos), pode subsumir, dessa forma, a multidão de identidades pré-coloniais, com sua coorte de comportamentos e desejos "abjetos", diz o autor.

3 "It is clear that the forms of sexual exchange brought about by colonialism were themselves both mirrors and consequences of the modes of economic exchange constituted the basis of colonial relations" (Young, 2002:181). 
Homoerotismo, hegemonia e história

Nos demais capítulos de@s Outr@s Cariocas. Interpelações e Identidades Homoeróticas no Rio de Janeiro, Carlos Figari, aplica, com método e graça, esses pressupostos delineados nas páginas iniciais, aos subseqüentes períodos históricos, do século XVII ao XX, discutindo e revelando práticas, sujeitos e personagens tão diversos quanto o "fanchono" Luiz Delgado de Quintal e seu romance com jovem e "trigueiro" ator carioca Doroteu Antunes; bispos e prelados "somitigos" e suas libertinagens conventuais; mancebos travestidos e "ninfas andróginas"; $e$ mesmo a "homoafeição" entre a Imperatriz Maria Leopoldina e Maria Graham.

Tal percurso, soberbamente povoado, permitiu ao autor explorar e pôr relevo em eixos fundamentais dessa genealogia do homoerotismo na maravilhosa Sodoma tropical. Notadamente, a predominância e gênese do padrão atividade/passividade, que Figari descreve como "uma formação discursiva hegemônica" que, após trinta anos da publicação de Da Hierarquia à Igualdade (Fry, 1982) e seus agudos insights, permanece poderosamente explicativo das dinâmicas sexuais de poder e de imposição de hierarquias. De tal forma que o padrão que liga "masculinidade/ poder/atividade" revela sua verdadeira articulação como uma "qualidade política" de extrema persistência e extensão, posicionando, assim, a sexualidade como uma metáfora operativa do poder, que se serve, abusa e assujeita os corpos Outros, reduzidos à sua passividade. Como, aliás, Figari desenvolve na análise da obra de Gilberto Freyre, de quem me permito citar mais uma vez, um trecho muito conhecido: "Através da submissão do muleque, seu companheiro de brinquedos expressivamente chamado 'leva-pancadas', iniciou-se muitas vezes o menino branco no amor físico" (Freyre, 1995 [1933]:50).

O autor também pôde considerar a constituição de uma esfera púbica no Rio de Janeiro e sua imbricação com a experiência homoerótica, a circulação de mercadorias e ideais, o amor romântico $e$ o individualismo, os salões de leitura $e$ fortalecimento do Estado, constituindo a separação entre esfera 
pública e privada. Assim, a ilusão da liberdade e a primazia do "Eu" abriram um campo de disciplinamento para o Estado republicano. E aí entram a "filosofia burguesa" e as disciplinas médicas e da psicanálise no século XX, cuidando de medicalizar a dissidência sexual como uma forma de controle social. Produzindo um ambiente ao mesmo tempo, e paradoxalmente, claustrofóbico $e$ obsessivo no que se refere à sexualidade, contradição representada brilhantemente, por exemplo, em Nelson Rodrigues: "Cada um de nós, individualmente, pode não ter o sexo na cabeça; mas o povo o tem. O pobre pra sobreviver precisa da pornografia" (Rodrigues, 1980:14).

Nas décadas finais do século passado, o autor retrata o momento, ainda recente e "quente", de reinvenções identitárias, que emergiu da decomposição do regime militar de 64, com seus impasses e linguagens políticas contestatórias. "Bichas" e trotkistas reúnem-se a feministas e negros, no bojo da reinvenção da política nos anos 70 . Os impasses da instituição de uma identidade homossexual politizada são considerados, em torno da proposição contestada do "ser" homossexual. Sob o advento da AIDS, da consolidação da democracia, do neoliberalismo e da chamada "globalização", a proliferação de identidades homossexuais no alvorecer do século XXI é estarrecedora e desconcertante - as paradas do orgulho gay, o mercado GLS e suas "tribos", a crescente organização política em bases identitárias e a internet. Tudo isso talvez revele uma derivação rumo à "assimilação", encarnada na figura respeitável do "gay cidadão", não diferenciado dos heterossexuais, a não ser pelo desejo, que seria apenas um detalhe, um elemento a mais na bricolagem das identidades na modernidade tardia. É claro que permanece um ruído de dissidência, inconformismo e exclusão. Porque esse "gay cidadão", como o cidadão médio, é idealizado como branco, de classe média, "bem-sucedido", straight acting, cosmopolita e liberal.

E aqui, por fim, me permitiria um breve comentário sobre a consolidação de novas hegemonias e normatividades 
Homoerotismo, hegemonia e história

homossexuais, que parecem possíveis apenas porque fingem esquecer as historicidades que as constituíram. O papel da teoria social crítica deveria ser desconfiar desses ufanismos de ocasião, que parecem empolgar o dance floor e a Universidade. $\mathrm{O}$ "eterno presente" e o paroxismo dos individualismos não deveriam nos enganar, fazendo-nos tomar as identidades como meros equivalentes intercambiáveis, num jogo de aparências e sinais que se conectam como peças coloridas de um brinquedo de criança. Como se não houvesse determinações em última instância, estruturas sociais opressivas, a desigualdade e o racismo. A performação estilizada de identidades sexuais, iluminadas pela luz âmbar da "noite GLS", não esgota as interrogações sobre a experiência das sexualidades homoeróticas e nem sobre a opressão social que forma seu cenário diuturno.

\section{Referências bibliográficas}

AlthUSSER, Louis. Aparelhos Ideológicos do Estado. Notas sobre Aparelhos Ideológicos de Estado. Rio de Janeiro, Graal, 1992.

FouCAUlt, Michel. Vigiar e Punir. História da Violência nas Prisões. Petrópolis, Vozes, 2004.

FREYRE, Gilberto. Casa Grande \& Senzala. Introdução à História da Sociedade Patriarcal no Brasil. $30^{a}$ edição. Rio de Janeiro, Editora Record, 1995 [1933].

FRY, Peter. Da Hierarquia à Igualdade: A Construção Histórica da Homossexualidade no Brasil. In: Pra Inglês Ver. Rio de Janeiro, Zahar Editores, 1982, pp.87-115.

RODRIGUES, Nelson. Asfalto Selvagem - I. Engraçadinha. Seus amores e seus pecados dos 12 aos 18 anos. São Paulo, Círculo do Livro S.A., 1980.

Young, Robert J. C. Colonial Desire. Hibridity in Theory, Culture and Race. London/New York, Routledge, 2002. 